\title{
Study on the correlation between postoperative mental flexibility, negative emotions, and quality of life in patients with thyroid cancer
}

\author{
Jieshu Lv, Linlin Zhu, Xianmei Wu, Hongyun Yue, Xiaowei Cui \\ Department of Head and Neck Surgery, Harbin Medical University Cancer Hospital, Harbin, China \\ Contributions: (I) Conception and design: J Lv, X Cui; (II) Administrative support: H Yue; (III) Provision of study materials or patients: L Zhu, X Wu; \\ (IV) Collection and assembly of data: All authors; (V) Data analysis and interpretation: J Lv, X Cui; (VI) Manuscript writing: All authors; (VII) Final \\ approval of manuscript: All authors. \\ Correspondence to: Xiaowei Cui. Harbin Medical University Cancer Hospital, No. 150, Haping Road, Nangang District, Harbin 150081, China. \\ Email: 18944608999@163.com.
}

\begin{abstract}
Background In recent years, the global incidence of thyroid cancer has increased year by year. The purpose of this study is to investigate the post-surgical psychological flexibility and negative feelings of patients with thyroid cancer and their association with quality of life.

Methods: A total of 82 patients with thyroid cancer were selected. The study utilized the Acceptance and Action Questionnaire 2nd edition (AAQ-II), the Cognitive Fusion Questionnaire (CFQ), and the Meaning in Life Questionnaire-the Presence of Meaning (MLQ-P). By quantifying psychological flexibility, we assessed the patient's experiential avoidance, cognitive fusion, and sense of life meaning. The Self-rating Depression Scale (SDS) and the Self-rating Anxiety Scale (SAS) were employed to evaluate depression and anxiety, respectively. Quality of life was evaluated with the Functional Assessment of Cancer Therapy-General (FACT-G).
\end{abstract}

Results: The mean AAQ-II, CFQ, MLQ-P, SAS, and SDS scores were 20.1 $\pm 9.2,27.5 \pm 10.7,23.0 \pm 5.7$, $47.7 \pm 13.3$, and $43.3 \pm 12.8$, respectively. In total, $24.4 \%$ and $45.1 \%$ of patients had depression and anxiety to some extent, respectively. The AAQ-II and CFQ scores were positively correlated with the SDS and SAS scores, and negatively correlated with the FACT-G score. The MLQ-P score was inversely correlated with the SDS and SAS scores, and was positively correlated with the FACT-G score. Logistic regression analysis indicated that the AAQ-II, CFQ, and MLQ-P were independent risk factors for quality of life.

Conclusions: Depression and anxiety are ubiquitous in patients with thyroid cancer following surgery. The psychological flexibility of patients is significantly negatively correlated with depression and anxiety and can dramatically influence quality of life.

Keywords: Thyroid cancer; psychological flexibility; negative feeling; quality of life

Submitted May 20, 2021. Accepted for publication Jul 26, 2021.

doi: $10.21037 /$ gs-21-424

View this article at: https://dx.doi.org/10.21037/gs-21-424

\section{Introduction}

With the increasing prevalence of ultrasound screening, the incidence rate of thyroid cancer has increased significantly in China. Although most thyroid cancers (especially papillary thyroid cancer) have a good prognosis, a cancer diagnosis is a severe adverse life event. It leads to substantial psychological stress, thus significantly affecting the quality of life of patients. Studies have shown that about $33-48 \%$ of cancer patients have different degrees of anxiety, depression, and other negative emotions (1). Psychological flexibility refers to the ability of individuals with independent consciousness to change certain behaviors 
based on personal values. Corresponding with psychological activity is psychological rigidity, which mainly includes empirical avoidance, cognitive integration, and lack of personal perspective. A previous study illustrated that the stronger the psychological rigidity of patients, the lower the psychological activity (2). McAteer et al. found that the psychological activity of patients with prostate cancer significantly affects the anxiety and quality of life of patients (3). However, there is no systematic study on the relationship between psychological activity and negative emotions, as well as quality of life in patients with thyroid cancer. The purpose of this study is to explore the relationship between psychological activity, negative emotions, and the quality of life of patients with thyroid cancer after surgery. This study provides a potential method for effectively improving negative emotions and patients' quality of life. We present the following article in accordance with the STROBE reporting checklist (available at https://dx.doi.org/10.21037/gs-21-424).

\section{Methods}

\section{General information}

A total of 82 patients with thyroid cancer after surgery in our department from October 2019 to December 2020 were selected as the research subjects. The inclusion criteria were as follows: (I) thyroid cancer was confirmed by pathology; (II) patients were 18 years old or above; (III) there was no history of mental illness in the past or at the time of inclusion; (IV) patients could understand the content of this study and agreed to participate in the study. The exclusion criteria were as follows: (I) rejection of participants; (II) the patient had severe organ dysfunction; (III) the patient had other malignant tumors. The questionnaire was distributed to patients for them to fill in by themselves. For patients with lower education level or older age, the researchers gave relevant explanations when filling out the questionnaire by themselves. A total of 82 questionnaires were distributed, and the response rate was $100 \%$. All procedures performed in this study involving human participants were in accordance with the Declaration of Helsinki (as revised in 2013). Informed consent was taken from all the patients. We will fully protect the privacy of patients, and the data collected will only be used for research purposes. However, the study was designed in 2019, and ethical review was not required for observational research at that time, as long as the patient signed an informed consent form.

\section{Data collection}

A self-designed questionnaire was used to collect the general information of patients, including age, gender, education level, marital status, duration of disease, medical payment (self-paid $v s$. medical insurance).

\section{Assessment of psychological flexibility}

The Acceptance and Action Questionnaire 2nd Edition (AAQ-II), the Cognitive Fusion Questionnaire (CFQ), and the Meaning in Life Questionnaire - the Presence of Meaning (MLQ-P) can quantify the main components of psychological rigidity. By exploring experiential avoidance, cognitive fusion, cognitive integration, and lack of value, we evaluated the psychological flexibility of patients (4). There are 7 items in the AAQ-II, and the score of each item is 1-7. The higher the score, the higher the degree of empirical avoidance. There are 9 items in the CFQ, and each item has 1-7 points. The higher the score, the higher the degree of cognitive integration. There are 5 items in the MLQ-P. The higher the score, the stronger the sense of meaning. Evaluating the degree of psychological stiffness of patients can reflect the psychological flexibility of patients.

\section{Negative emotion assessment}

The Self-rating Depression Scale (SDS) and the Self-rating Anxiety Scale (SAS) were used to quantify the degree of depression and anxiety, respectively. Each scale contains 20 items. Each item is $1-4$ points, the score is multiplied by 1.25 , and the integer of the result is used as the standardized score of depression and anxiety. The higher the total score, the more severe the depression or anxiety.

\section{Quality of life assessment}

The Functional Assessment of Cancer Therapy - General (FACT-G) was used to evaluate quality of life (5). The scale can evaluate 4 dimensions of quality of life: physiological status (7 items, total score 28 ), social/family status (7 items, total score 28$)$, emotional status (6 items, total score 24$)$, and functional status (7 items, total score 28).

\section{Statistical analysis}

SPSS 22.0 was used for statistical analysis. Continuous normally distributed data were expressed as mean $\pm \mathrm{SD}$, and 
Table 1 General information of participating patients

\begin{tabular}{lc}
\hline Variables & Count \\
\hline Age (years) & $37.9 \pm 10.3$ \\
Sex, $\mathrm{n}(\%)$ & $46(56.1)$ \\
Male & $36(43.9)$ \\
Female & $25.4 \pm 8.6$ \\
Course of the disease & \\
Degree of education, $\mathrm{n}(\%)$ & $41(50.0)$ \\
Senior high school and below & $41(50.0)$ \\
Undergraduate and above & \\
Payment method, $\mathrm{n}(\%)$ & $70(85.4)$ \\
Covered by medical insurance & $12(14.6)$ \\
Paid by themselves & \\
Marital status, $\mathrm{n}$ (\%) & $27(32.9)$ \\
Unmarried & $48(58.5)$ \\
Married & $7(8.6)$ \\
Divorced or widowed & \\
\hline
\end{tabular}

Table 2 Mental activity, anxiety, and depression scores of participating patients

\begin{tabular}{lccccc}
\hline Tests & AAQ-II & CFQ & MLQ-P & SAS & SDS \\
\hline Score & $20.1 \pm 9.2$ & $27.5 \pm 10.7$ & $23.0 \pm 5.7$ & $47.7 \pm 13.3$ & $43.3 \pm 12.8$ \\
\hline AAQ-II, Acceptance and Action Questionnaire 2nd edition; \\
CFQ, Cognitive Fusion Questionnaire; MLQ-P, Meaning in \\
Life Questionnaire-the Presence of Meaning; SAS, Self-rating \\
Anxiety Scale; SDS, Self-rating Depression Scale.
\end{tabular}

count data were expressed as percentages or rates. Pearson correlation was utilized to calculate the correlation between psychological flexibility score and anxiety, depression, and quality of life. The risk factors of negative emotion and quality of life were identified by regression analysis. The corresponding odds ratios (ORs) and $95 \%$ confidence intervals $(\mathrm{CIs})$ were calculated. Bilateral $\mathrm{P}<0.05$ indicated that the difference was statistically significant.

\section{Results}

\section{General information of patients}

As shown in Table 1, the average age of the 82 patients was $37.9 \pm 10.3$ years old. Males accounted for $56.1 \%$, while
Table 3 Quality of life scores of patients

\begin{tabular}{lcccc}
\hline Status & Items & Maximum & Minimum & Average \\
\hline Physiological status & 7 & 28 & 9 & $21.3 \pm 5.1$ \\
Social/family status & 7 & 28 & 10 & $20.1 \pm 5.2$ \\
Emotional status & 6 & 24 & 8 & $18.7 \pm 3.3$ \\
Functional status & 7 & 28 & 12 & $20.5 \pm 3.4$ \\
Quality of life (FACT-G) & 27 & 106 & 49 & $80.6 \pm 16.3$ \\
\hline
\end{tabular}

FACT-G, Functional Assessment of Cancer Therapy-General.

females accounted for $42.9 \%$. The average course of the disease was $25.4 \pm 8.6$ months. Among the patients, $85.4 \%$ of them were paid by medical insurance and $58.5 \%$ were married.

\section{Psychological flexibility and negative emotion scores of patients}

As shown in Table 2, the AAQ-II, CFQ, MLQ-P, SAS, and SDS scores of participating patients were 20.1 \pm 9.2 , $27.5 \pm 10.7,23.0 \pm 5.7,47.7 \pm 13.3$, and $43.3 \pm 12.8$, respectively. Among them, 62 (75.6\%), $16(19.5 \%), 3$ (3.7\%), and $1(1.2 \%)$ patient had no, mild, moderate, and severe depression, respectively. Additionally, 45 (54.9\%), 25 (30.5\%), 7 (8.5\%), and $5(6.1 \%)$ patients had no, mild, moderate, and severe anxiety, respectively.

\section{Quality of life in patients}

As shown in Table 3, the total score of patients' quality of life was $80.61 \pm 16.3$. The scores of each dimension from high to low were physiological status $(21.3 \pm 5.1)$, functional status (20.5 \pm 3.4$)$, social/family status $(20.1 \pm 5.2)$, and emotional status $(18.7 \pm 3.3)$ points.

\section{Correlation between psychological flexibility, negative emotions, and quality of life}

As shown in Table 4, patients' experiential avoidance and cognitive integration were significantly positively correlated with anxiety and depression. In contrast, the sense of meaning of life was significantly negatively correlated with anxiety and depression. Quality of life was negatively associated with experiential avoidance and cognitive integration, positively correlated with the sense of life meaning, and negatively correlated with anxiety and depression. 


\section{Regression analysis of patients' quality of life and psychological flexibility}

According to the average quality of life (80.6), the patients were divided into 2 groups: high quality of life group and

Table 4 Pearson correlation analysis among psychological flexibility, negative emotion, and quality of life ( $\mathrm{n}=82$, R value)

\begin{tabular}{lcccccc}
\hline Variables & AAQ-II & CFQ & MLQ-P & SAS & SDS & FACT-G \\
\hline AAQ-II & - & - & - & - & - & - \\
CFQ & $0.47^{\star \star \star}$ & - & - & - & - & - \\
MLQ-P & $-0.32^{\star \star}$ & $-0.25^{\star}$ & - & - & - & - \\
SAS & $0.29^{\star}$ & $0.30^{\star}$ & $-0.23^{\star}$ & - & - & - \\
SDS & $0.31^{\star \star}$ & $0.25^{\star}$ & $-0.27^{\star}$ & $0.22^{\star}$ & - & - \\
FACT-G & $-0.34^{\star \star}$ & $-0.30^{\star \star}$ & $0.59^{\star \star \star}$ & $-0.47^{\star \star \star}$ & $-0.35^{\star \star}$ & - \\
\hline
\end{tabular}

AAQ-II, Acceptance and Action Questionnaire 2nd edition; CFQ, Cognitive Fusion Questionnaire; MLQ-P, Meaning in Life Questionnaire-the Presence of Meaning; SAS, Self-rating Anxiety Scale; SDS, Self-rating Depression Scale; FACT-G, Functional Assessment of Cancer Therapy-General. *, $\mathrm{P}<0.05$; **, $\mathrm{P}<0.01$; ${ }^{* *}, \mathrm{P}<0.001$. poor quality of life group. The univariate comparison between the 2 groups is shown in Table 5. There were significant differences in the scores of the AAQ-II, CFQ, and MLQ-P between the high quality of life group and the low quality of life group (all $\mathrm{P}<0.001$ ). Binary logistic regression analysis showed that $\mathrm{AAQ}-\mathrm{II}(\mathrm{OR}=1.11,95 \%$ CI: $1.00-1.22, \mathrm{P}=0.03)$, CFQ (OR $=1.10,95 \% \mathrm{CI}: 1.01-$ $1.21, \mathrm{P}=0.02)$, and MLQ-P (OR $=0.70,95 \%$ CI $0.58-0.84$, $\mathrm{P}<0.001)$ were risk factors for quality of life.

\section{Discussion}

This study suggests that $24.4 \%$ and $45.1 \%$ of patients with thyroid cancer have different degrees of depression and anxiety, respectively. Patients' psychological flexibility is significantly related to anxiety and depression, and it is a risk factor affecting patients' quality of life.

Hayes et al. first proposed psychological activity in the process of establishing acceptance and commitment therapy (6). Psychological flexibility is an essential part of individual mental health. Many studies have shown that poor psychological flexibility is related to the onset of

Table 5 Regression analysis of the quality of life and psychological flexibility of patients

\begin{tabular}{|c|c|c|c|c|}
\hline Variables & High life quality $(n=41)$ & Low life quality $(n=41)$ & Statistical & $P$ value \\
\hline Age (year) & $38.9 \pm 10.2$ & $36.9 \pm 10.6$ & 0.87 & 0.39 \\
\hline Sex (male/female) & $20 / 21$ & 26/15 & 1.78 & 0.27 \\
\hline Course of the disease (months) & $24.9 \pm 7.5$ & $25.8 \pm 9.6$ & -0.47 & 0.64 \\
\hline Degree of education, $\mathrm{n}(\%)$ & & & 0.98 & 0.32 \\
\hline Senior high school or above & $18(43.9)$ & $23(56.1)$ & & \\
\hline Undergraduate or above & $23(56.1)$ & $18(43.9)$ & & \\
\hline Payment method, n (\%) & & & 3.51 & 0.12 \\
\hline Covered by medical insurance & $32(78.0)$ & $38(92.7)$ & & \\
\hline Paid by themselves & $9(22.0)$ & $3(7.3)$ & & \\
\hline Marital status, $\mathrm{n}(\%)$ & & & 1.41 & 0.49 \\
\hline Unmarried & $14(34.1)$ & $13(31.7)$ & & \\
\hline Married & $25(61.0)$ & $23(56.1)$ & & \\
\hline Divorced/widowed & $2(4.9)$ & $5(12.2)$ & & \\
\hline AAQ-II & $15.1 \pm 7.0$ & $25.0 \pm 8.5$ & -5.76 & $<0.001$ \\
\hline CFQ & $22.1 \pm 9.4$ & $33.0 \pm 9.0$ & -5.36 & $<0.001$ \\
\hline MLQ-P & $26.3 \pm 5.3$ & $19.6 \pm 3.9$ & 6.52 & $<0.001$ \\
\hline
\end{tabular}

AAQ-II, Acceptance and Action Questionnaire 2nd edition; CFQ, Cognitive Fusion Questionnaire; MLQ-P, Meaning in Life Questionnairethe Presence of Meaning. 
many mental disorders. For example, Shepherd et al. found that patients with facial damage have poor psychological flexibility and are more inclined to the values of escaping and lacking (7). Psychological flexibility significantly affects the anxiety, depression, and other negative emotions of cancer patients. For example, a study of 122 breast cancer patients found that more than half of the patients had negative emotions. The empirical avoidance of patients was significantly related to anxiety, depression, and generalized affective disorder (8).

This study evaluated patients' psychological flexibility through empirical avoidance, cognitive integration, and lack of value. Experiential avoidance primarily refers to the form and frequency of an individual's attempt to change an unpleasant or disgusting experience. Empirical avoidance has been proven to be directly related to postoperative emotional disorder in patients with breast cancer (9). Brown et al. suggested that empirical avoidance may be a potential mechanism of chronic pain in cancer patients with emotional disorders (10). Cognitive fusion refers to the confusion of an individual's thoughts and actual events. In other words, the patient does not correctly distinguish between the "idea" and the actual situation. Sense of life significance/value refers to the positive attitude of patients towards life. Jim et al. reported that positive or negative values to treat breast cancer after surgery can predict the life attitude of patients 2 years later (11).

Consistent with previous reports, $24.4 \%$ and $45.1 \%$ of patients with thyroid cancer had different degrees of depression and anxiety, respectively. A survey of 118 patients with thyroid cancer showed that $43.3 \%$ of them had anxiety or depression (12). Another study of 136 patients with thyroid cancer showed that $62.5 \%$ and $17.9 \%$ of the patients had anxiety and depression, respectively (13).

In this study, patients' psychological flexibility was significantly correlated with anxiety and depression. According to Hayes' theory, when patients try to control their anxiety, they will inevitably think of fear and cause a series of discomforts. Cognitive fusion can bring patients into their own "wishful thinking" and then trigger anxiety. Improving patients' sense or significance of life value is helpful for improving the depression of cancer patients (14).

The quality of life of patients with thyroid cancer after surgery is reduced, and is affected by patients' psychological flexibility. A British survey suggested that the quality of life of patients with thyroid cancer was lower than the regional norm (15). Studies found that although thyroid cancer has a good prognosis, the quality of life of patients is still significantly lower than that of the general population. With the passage of time, the emotional function, fatigue, pain, and other symptoms of patients will be improved (16). Some clinical trials suggest that psychological flexibility is related to quality of life and well-being (17), which is consistent with the findings of this study.

Following psychological counseling for psychological flexibility may help to improve the life of patients. For example, doctors explain the knowledge of thyroid cancer to patients and help them establish a correct view of the disease. In addition, doctors can explain the prognosis of thyroid cancer to patients with examples and help them eliminate psychological pressure. During the follow-up, the problems will be treated in time.

In conclusion, this study suggests that patients with thyroid cancer generally have different degrees of anxiety and depression, and other negative emotions. Patients' psychological flexibility was negatively correlated with anxiety and depression, and affected their quality of life. Therefore, in the process of diagnosis, treatment, and follow-up, attention should be paid to patients' psychological flexibility and corresponding psychological counseling should be provided, which is helpful for improving the quality of life of patients.

\section{Acknowledgments}

Funding: None.

\section{Footnote}

Reporting Checklist: The authors have completed the STROBE reporting checklist. Available at https://dx.doi. org/10.21037/gs-21-424

Data Sharing Statement: Available at https://dx.doi. org/10.21037/gs-21-424

Conflicts of Interest: All authors have completed the ICMJE uniform disclosure form (available at https://dx.doi. org/10.21037/gs-21-424). The authors have no conflicts of interest to declare.

Ethical Statement: The authors are accountable for all aspects of the work in ensuring that questions related to the accuracy or integrity of any part of the work are appropriately investigated and resolved. All procedures performed in this study involving human participants were 
in accordance with the Declaration of Helsinki (as revised in 2013). Informed consent was taken from all the patients. We will fully protect the privacy of patients, and the data collected will only be used for research purposes. However, the study was designed in 2019, and ethical review was not required for observational research at that time, as long as the patient signed an informed consent form.

Open Access Statement: This is an Open Access article distributed in accordance with the Creative Commons Attribution-NonCommercial-NoDerivs 4.0 International License (CC BY-NC-ND 4.0), which permits the noncommercial replication and distribution of the article with the strict proviso that no changes or edits are made and the original work is properly cited (including links to both the formal publication through the relevant DOI and the license). See: https://creativecommons.org/licenses/by-nc-nd/4.0/.

\section{References}

1. Lehto US, Tenhola H, Taari K, et al. Patients' perceptions of the negative effects following different prostate cancer treatments and the impact on psychological well-being: a nationwide survey. Br J Cancer 2017;116:864-73.

2. Daks JS, Peltz JS, Rogge RD. Psychological flexibility and inflexibility as sources of resiliency and risk during a pandemic: Modeling the cascade of COVID-19 stress on family systems with a contextual behavioral science lens. J Contextual Behav Sci 2020;18:16-27.

3. McAteer G, Gillanders D. Investigating the role of psychological flexibility, masculine self-esteem and stoicism as predictors of psychological distress and quality of life in men living with prostate cancer. Eur J Cancer Care (Engl) 2019;28:e13097.

4. Xiong A, Lai X, Wu S, et al. Relationship Between Cognitive Fusion, Experiential Avoidance, and ObsessiveCompulsive Symptoms in Patients With ObsessiveCompulsive Disorder. Front Psychol 2021;12:655154.

5. Cella DF, Tulsky DS, Gray G, et al. The Functional Assessment of Cancer Therapy scale: development and validation of the general measure. J Clin Oncol 1993;11:570-9.

6. Hayes SC, Luoma JB, Bond FW, et al. Acceptance and commitment therapy: model, processes and outcomes. Behav Res Ther 2006;44:1-25.

7. Shepherd L, Reynolds DP, Turner A, et al. The role of psychological flexibility in appearance anxiety in people who have experienced a visible burn injury. Burns
2019;45:942-9.

8. González-Fernández S, Fernández-Rodríguez C, MotaAlonso MJ, et al. Emotional state and psychological flexibility in breast cancer survivors. Eur J Oncol Nurs 2017;30:75-83.

9. Aguirre-Camacho A, Pelletier G, González-Márquez A, Blanco-Donoso LM, García-Borreguero P, MorenoJiménez B. The relevance of experiential avoidance in breast cancer distress: insights from a psychological group intervention. Psychooncology 2017;26:469-75.

10. Brown SL, Roush JF, Marshall AJ, et al. The Intervening Roles of Psychological Inflexibility and Functional Impairment in the Relation between Cancer-related Pain and Psychological Distress. Int J Behav Med 2020;27:100-7.

11. Jim HS, Richardson SA, Golden-Kreutz DM, et al. Strategies used in coping with a cancer diagnosis predict meaning in life for survivors. Health Psychol 2006;25:753-61.

12. Buchmann L, Ashby S, Cannon RB, et al. Psychosocial distress in patients with thyroid cancer. Otolaryngol Head Neck Surg 2015;152:644-9.

13. Tagay S, Herpertz S, Langkafel M, et al. Health-related Quality of Life, depression and anxiety in thyroid cancer patients. Qual Life Res 2006;15:695-703.

14. Breitbart W, Rosenfeld B, Gibson C, et al. Meaningcentered group psychotherapy for patients with advanced cancer: a pilot randomized controlled trial. Psychooncology 2010;19:21-8.

15. McIntyre C, Jacques T, Palazzo F, et al. Quality of life in differentiated thyroid cancer. Int J Surg 2018,50:133-6.

16. Gamper EM, Wintner LM, Rodrigues M, et al. Persistent quality of life impairments in differentiated thyroid cancer patients: results from a monitoring programme. Eur J Nucl Med Mol Imaging 2015;42:1179-88.

17. Hoffmann D, Rask CU, Hedman-Lagerlöf E, et al. Efficacy of internet-delivered acceptance and commitment therapy for severe health anxiety: results from a randomized, controlled trial. Psychol Med 2020. [Epub ahead of print]. doi: 10.1017/S0033291720001312.

(English Language Editor: C. Betlazar-Maseh)

Cite this article as: $\mathrm{Lv} \mathrm{J}, \mathrm{Zhu} \mathrm{L}, \mathrm{Wu} \mathrm{X}$, Yue H, Cui X. Study on the correlation between postoperative mental flexibility, negative emotions, and quality of life in patients with thyroid cancer. Gland Surg 2021;10(8):2471-2476. doi: 10.21037/gs-21424 